\title{
Outbreak Investigation of Cholera in a Slum of Northern India
}

\author{
Manoj Kumar*, Vijay Lakshmi Sharma \\ Centre for Public Health, Panjab University, Chandigarh, India \\ Email: ${ }^{*}$ mkcph@pu.ac.in
}

Received 1 August 2014; revised 1 September 2014; accepted 1 October 2014

Copyright (C) 2014 by authors and Scientific Research Publishing Inc.

This work is licensed under the Creative Commons Attribution International License (CC BY). http://creativecommons.org/licenses/by/4.0/

(c) $\underset{\mathrm{EY}}{\mathrm{B}}$ Open Access

\begin{abstract}
Cholera is one of the oldest and best understood endemic diseases. An actual bacterial enteric disease, it is characterized in its severe form by sudden onset, profuse painless watery stools (ricewater stool), nausea and profuse vomiting early in the course of illness. Endemic and pandemics are strongly linked to the consumption of unsafe water, poor hygiene, poor sanitation and crowded living conditions. A rapid survey was conducted for the outbreak investigation on August 4, 2008. The objectives were to investigate the outbreak, risk factors for cholera and recommend control measures immediately. Questionnaire based random convenient sample based investigative study. 60 families were contacted by the public health students. Approximate 300 individuals were screened for cholera cases. Simultaneously six water samples were also collected from the contacted family. Microbiological test for Vibrio cholera and $E$. coli was conducted. Randomly six water samples were collected from the Rajive colony. Microbiological test for Vibrio cholera and $E$. coli was conducted from the department of Microbiology, PU. Vibrio cholera and $E$. coli were found absent, in all the samples. One sample was found positive for unidentified bacteria.
\end{abstract}

\section{Keywords}

Cholera, Slum

\section{Introduction}

Cholera has been present in India since ancient times. During the $19^{\text {th }}$ century, several pandemics of cholera originated from India and spread to western countries. Currently the seventh pandemic which began in 1961 in Indonesia is still continuing. It has involved more than 80 countries in Asia, Africa and Europe.

Cholera is both an epidemic and endemic disease. The epidemicity and endemictiy of a disease will depend on Characteristics of the agent, and those of the system. Characteristics of the agent which influence its distribu-

\footnotetext{
${ }^{*}$ Corresponding author.
} 
tion include its ability to survive in a given environment, its virulence, the average number of organisms required to cause infection, etc. Characteristics of the system which affect the distribution of the agent include the number of susceptible, and the opportunities it provides for transmission of the infection. Global experience has shown that the introduction of cholera into any country cannot be prevented, but cholera can create a problem only in areas where sanitation is defective.

Epidemics of cholera are characteristically abrupt and often create an acute public health problem. They have a high potential to spread fast and cause death. Often-times, by the time control measures are instituted the epidemic has already reached its peak and is waning. Thus, cholera epidemic in a community is self-limiting. It tends to decline after reaching its peak. This is attributed to the acquisition of temporary immunity, as well as due to the occurrence of a large number of sub clinical cases.

The practical successes of anticontagionists were not limited to their victories over quarantines. Their operations against "filth" increased greatly their prestige. While it was difficult for the contagionists to prove that a respective epidemic would have been even worse without quarantines; health improvements after removal of "filth" seemed to be causally related to the latter action. Barcelona and Alicante did not experience further yellow fever epidemics after such campaigns in 1827, respectively 1804. The General Board of Health could point in the cholera of 1848-1849 to the immunity of its cleaned "model houses" [1].

Peter Baldwin seeks to challenge the widely held, reductionist belief that "it was not the nature of the disease which specified how it would be prevented and limited, but the kind of political regime under epidemic attack". The more interesting question, and one that Baldwin also poses but answers less satisfactorily, is whether these dynamics determined the nature of the political systems themselves. He coins the appropriate term "neoquarantinist" to describe the panoply of measures that served to control epidemiological outbreaks as opposed to preventing their occurrence altogether. The emergence of these adaptive strategies is crucial to Baldwin's interpretation of the post-cholera period, and one cannot dispute the emphasis he places on them [2].

By the end of the 19th century, cholera epidemics no longer appeared in Europe and North America. The reasons for this are uncertain, but standards of living had risen and many communities had made major changes in sanitation practices and established permanent boards of health. As part of the transformation to the germ theory, medical thought had changed in many ways as well. In 1831, most physicians believed cholera to be a nonspecific, noncontagious miasmatic condition that favored the morally and physically predisposed. By the end of the 19th century, although the miasmatic interpretation still had influence, cholera was primarily understood to be a specific contagious disease caused by a particular microscopic organism [3].

Ideas relating sickness to personal morality have long been important in European and American thought. In the Judeo-Christian tradition, sickness has often been seen as divine punishment for sin. Cures for sexually transmitted diseases, including syphilis, have been criticized in the belief that cures would encourage immoral behavior. Moral and ethical issues associated with sex, food, drink, work, and emotions have also been connected with the possibility of contracting or spreading disease [4].

Until Robert Koch identified the cholera bacillus in 1883; science continued to favor anticontagionism. Leading anticontagionists or contingent contagionists included Max von Pettenkofer and South wood Smith. According to the contingent contagionist perspective, cholera could be contagious, but only under particular circumstances [5]. The existence of the cholera bacillus did not necessarily prove cholera's contagiousness either; some argued that the bacillus was the product of the disease, not its cause. Another issue was how to explain the existence of healthy carriers-people who had the cholera bacillus in their bodies but who were not sick. In practice, public health measures often involved a blend of contagionist and anticontagionist views.

Cholera was the classic epidemic disease of the nineteenth century, as the plague had been for the fourteenth. Its defeat was a reflection not only of progress in medical knowledge but of enduring changes in American social thought. Rosenberg has focused his study on New York City, the most highly developed center of this new society. Carefully documented, full of descriptive detail, yet written with an urgent sense of the drama of the epidemic years, this narrative is as absorbing for general audiences as it is for the medical historian. In a new Afterword, Rosenberg discusses changes in historical method and concerns since the original publication of The Cholera Years [6] [7].

Epidemic of cholera are frequent, striking adults as well as children. Epidemiological studies have shown that cholera is responsible for about 5 - 10 per cent of all acute diarrhea cases in non epidemic situation. Global experience of the current pandemic has shown that cholera can get introduced into any country but can create 
problem only in areas where other acute enteric infections are endemic, i.e. where sanitation is defective.

Although cholera occurs from time to time in Chandigarh slums, and in Tricity, Large number of reports started appearing in July, 2008 from areas in and around Chandigarh. To investigate the suspected epidemic, we have conducted a rapid survey for this outbreak investigation on August, 4, 2008.

\section{Methodology}

In July 2008, outbreaks of Cholera illness were reported from Rajive colony, Panchkula. This provided a challenge for the centre for public health of Panjab University, Chandigarh to identify risk factors and network with resources available in the Panchkula for outbreak response. The objectives were to investigate the outbreak, risk factors for cholera and recommend control measures immediately.

The investigation team was from centre for public health of Panjab University, Chandigarh. The team identified part of total cases that occurred in this colony by house-to-house survey. Risk factors were assessed by using a questionnaire. Laboratory investigations for microbiological test of water samples were done from the department of microbiology, Panjab University, Chandigarh.

A cross-sectional study was conducted by using random sampling method in a sample size of 300 individuals. Self structured questionnaire regarding sanitation and hygiene, quality of water used for drinking and domestic purposes was collected. About 60 families were contacted by the public health team. Approximate 300 individuals were screened for cholera cases. Simultaneously six water samples were also collected from the contacted family. Microbiological test for Vibrio cholera and E. coli was conducted.

It can be concluded that poor sanitary and unhygienic conditions may be responsible for the Cholera cases occurred in rainy season in of July, 2008.

\section{Results}

Table 1, shows that almost equal numbers of cases were observed from both sex. More cases were reported from the age group 20 - 60 years. More males were affected in $<20$ years of age groups as compared. And only two female cases were reported from the $>60$ years age group.

According to Table 2, Out of 17 cases, 10 cases were from conformed and suspected category. Equal numbers of cases were reported for conformed and suspected diagnoses from males and females.

Randomly six water samples were collected from the Rajive colony. Microbiological test for Vibrio cholera and E. coli was conducted from the department of Microbiology, Panjab University, Chandigarh. Vibrio cholera and E. coli were found absent, in all the samples. One sample was found positive for unidentified bacteria.

Table 1. Age group and sex distribution of cases.

\begin{tabular}{cccc}
\hline Age Group & Male & Female & Total \\
\hline$<20$ years & 3 & 1 & 4 \\
$20-60$ years & 6 & 5 & 11 \\
$>60$ & 0 & 8 & 2 \\
Total & 9 & 8 & 17 \\
\hline
\end{tabular}

Table 2. Distribution of cases according to diagnosis.

\begin{tabular}{cccc}
\hline Diagnosis & Male & Female & Total \\
Conformed & 2 & 3 & 5 \\
Suspected & 2 & 3 & 3 \\
Not conformed & 4 & 9 & 7 \\
Total & 8 & 9 & 17 \\
\hline
\end{tabular}




\section{Discussion}

The city of Hamburg was hit by one of the greatest urban disasters of the century: a cholera epidemic that within six weeks left ten thousand people dead and many more suffering the appalling symptoms of this terrible disease. Drawing on a mass of detailed source material, this book presents a graphic portrayal of a great European city in the throes of a major social and political crisis [8]. Cholera is entirely multiform, as are typhoid fever, pneumonia, cerebrospinal meningitis and all infectious diseases without exception [9].

Despite the continued discussion about the cause of cholera, over the course of the 19th century the actual treatment of the disease did not change much. Patients with families were cared for at home. Physicians, when called, would use such characteristic treatments as bleeding or opium. Homeopathic methods were popular among the middle and upper classes, as were other eclectic treatments, and all manner of dietary and hygienic regimens were promoted in newspapers and books. Those without families might find themselves in charity hospitals, which could become grim places indeed during an epidemic. Preachers gave sermons on the meaning of cholera for both individuals and society. Riots ensued due to popular revolt against mass burials [10].

As part of the transformation to the germ theory, medical thought had changed in many ways as well. In 1831, most physicians believed cholera to be a nonspecific, noncontagious miasmatic condition that favored the morally and physically predisposed [11].

The main symptom of cholera is diarrhea. Cases range from symptom less to severe infections. The majority of infections are mild or asymptomatic. Typical cases are characterized by the sudden onset of profuse, effortless, watery diarrhea followed by vomiting, rapid dehydration, muscular craps and suppression of urine. Unless there is rapid replacement of fluid and electrolytes, the case fatality may be as high as 30 to 40 per cent. The village leaders helped the investigation team in instituting standard hygienic measures for controlling the outbreak immediately

Vibrio transmission is readily possible in a community with poor environmental sanitation. The environmental factor of importance includes contaminated water and food. Flies may carry V. cholerae. Numerous social factors have also been responsible for the endemicity of cholera in India. These comprise certain human habit favoring water and soil pollution, low standards of personal hygiene, lack of education and poor quality of life.

Transmission occurs from man to man via faecally contaminated waste: Uncontrolled water sources such as well, lakes ponds, streams and rivers pose a great threat, Contaminated food and drinks: Ingestion of contaminated food and drinks have been associated with outbreaks of cholera. Bottle-feeding could be significant risk factor for infants. Fruits and vegetables washed with contaminated water can be a source of infection. After preparation, cooked food maybe contaminated through contaminated hands and flies. There is growing opinion that complex interaction of contaminated food, water and environment rather than through public drinking water supplies and direct contact: In developing countries a considerable proportion of cases may result from secondary transmission i.e. person to person transmission through contaminated fingers while carelessly handling excreta and vomit of patients. Incubation period is from few hours up to 5 days, but commonly $1-2$ days.

Leakages in water pipes coupled with poor environmental sanitation were identified as reasons for contamination of drinking water. Health education, immediate repair of leaking pipes and chlorination of water supply led to an early control of the outbreak.

\section{Conclusion}

It can be concluded that poor sanitary and unhygienic conditions may be responsible for the Cholera cases occurred in rainy season in of July, 2008.

\section{Recommendations}

Taking measure given below can minimize the risk of an outbreak of cholera and its spread. There are no other alternative for the control of outbreak of Cholera.

1) Provision of safe water;

2) Adopting safe practices in food handling;

3) Sanitary disposal of human waste;

4) Personal and domestic hygienic practices;

5) Particular attention should be given in the pre-monsoon periods before the expected seasonal increase of wa- 
ter-borne diseases: however these measures are expected to be in place round the year;

6) Arrange random checks for water quality for coliform organisms;

7) Ensure that the health personnel are adequately trained in oral rehyderation therapy and that recommended guidelines are followed in hospitals.

The above steps are required both as long term measure to prevent Cholera, as well as measures to be taken in focal area where an outbreak is anticipated. Community participation is essential to prevent an outbreak so that safe practices are followed for storing water and for food handling.

\section{Acknowledgements}

We are thankful to the Centre for Public Health and Department of Microbiology, Panjab University for their indispensable assistance.

\section{References}

[1] Ackerknecht, E.H. (1948) Anticontagionism between 1821 and 1867. Bulletin of the History of Medicine, 22, $562-593$.

[2] Baldwin, P. (1999) Contagion and the State in Europe, 1830-1930. Cambridge University Press, Cambridge. http://dx.doi.org/10.1017/CBO9780511497544

[3] Briggs, A. (1961) Cholera and Society in the Nineteenth Century. Past and Present, 19, 76-96. http://dx.doi.org/10.1093/past/19.1.76

[4] Delaporte, F. (1986) Disease and Civilization: The Cholera in Paris, 1832. MIT Press, Cambridge, MA, and London.

[5] Howard-Jones, N. (1975) The Scientific Background of the International Sanitary Conferences, 1851-1938. World Health Organization, Geneva.

[6] Pelling, M. (1978) Cholera, Fever and English Medicine, 1825-1865. Oxford University Press, New York.

[7] Rosenberg, C.E. The Cholera Years: The United States in 1832, 1849, and 1866. Chicago and London, University of Chicago Press, 1962, 1987.

[8] Evans, R. (1987) Death in Hamburg: Society and Politics in the Cholera Years, 1830-1910. Clarendon Press, Oxford.

[9] Frieden, N. (1977) The Russian Cholera Epidemic, 1892-93, and Medical Professionalization. Journal of Social History, 10, 538-559. http://dx.doi.org/10.1353/jsh/10.4.538

[10] Arnold, D. (1986) Cholera and Colonialism in British India. Past and Present, 113, 118-151. http://dx.doi.org/10.1093/past/113.1.118

[11] Leiker, J. and Powers, R. (1998) Cholera among the Plains Indians: Perceptions, Causes, Consequences. The Western Historical Quarterly, 29, 317-340. http://dx.doi.org/10.2307/970577 
Scientific Research Publishing (SCIRP) is one of the largest Open Access journal publishers. It is currently publishing more than 200 open access, online, peer-reviewed journals covering a wide range of academic disciplines. SCIRP serves the worldwide academic communities and contributes to the progress and application of science with its publication.

Other selected journals from SCIRP are listed as below. Submit your manuscript to us via either submit@scirp.org or Online Submission Portal.
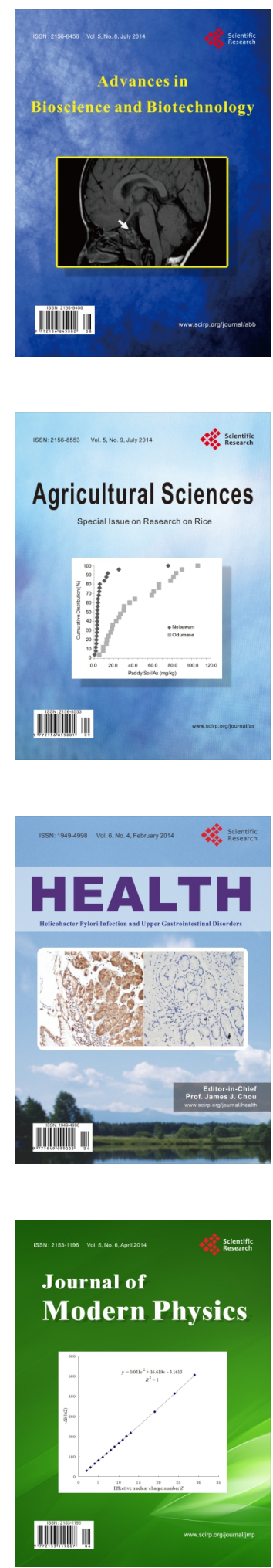
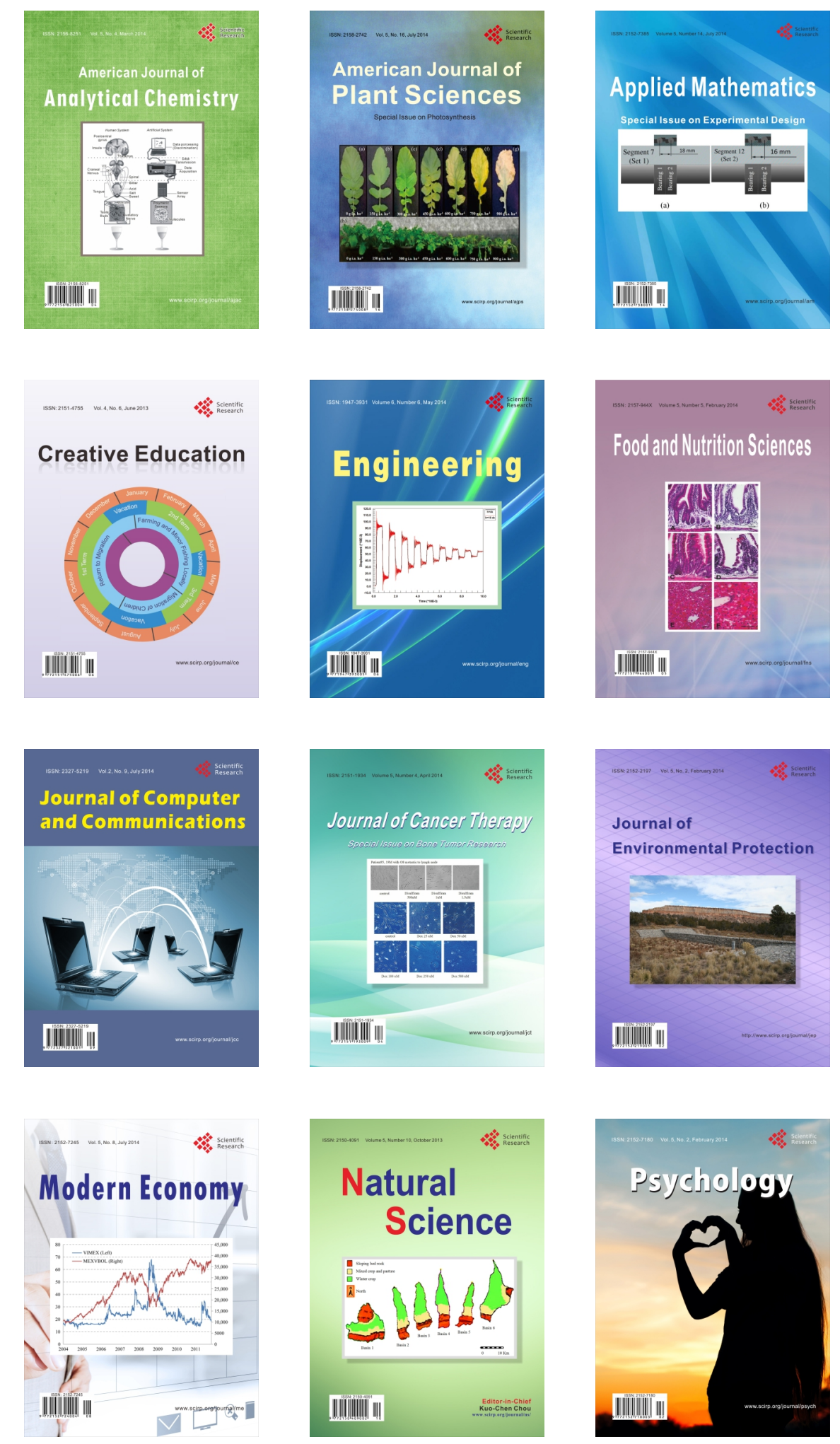